\title{
Life on the edge: behavioural and physiological responses of Verreaux's sifakas (Propithecus verreauxi) to forest edges
}

\author{
Klara Dinter $^{1}$, Michael Heistermann ${ }^{2}$, Peter M. Kappeler ${ }^{1,3}$, and Claudia Fichtel ${ }^{1}$ \\ ${ }^{1}$ Behavioral Ecology and Sociobiology Unit, German Primate Center, \\ Kellnerweg 4, 37077 Göttingen, Germany \\ ${ }^{2}$ Endocrinology Laboratory, German Primate Center, Kellnerweg 4, 37077 Göttingen, Germany \\ ${ }^{3}$ Department of Sociobiology and Anthropology, Johann-Friedrich-Blumenbach Institute for Zoology and \\ Anthropology, Georg-August University, Kellnerweg 6, 37077 Göttingen, Germany
}

Correspondence: Claudia Fichtel (claudia.fichtel@gwdg.de)

Received: 19 August 2020 - Revised: 13 December 2020 - Accepted: 16 December 2020 - Published: 9 February 2021

\begin{abstract}
Forest edges change micro-environmental conditions, thereby affecting the ecology of many forestdwelling species. Understanding such edge effects is particularly important for Malagasy primates because many of them live in highly fragmented forests today. The aim of our study was to assess the influence of forest edge effects on activity budgets, feeding ecology, and stress hormone output (measured as faecal glucocorticoid metabolite - fGCM - levels) in wild Verreaux's sifakas (Propithecus verreauxi), a group living, arboreal lemur. We observed five habituated groups: three living in the forest interior and two at an established forest edge. There was no difference in average daily temperatures between edge and interior habitats; however, within the edge site, the average daily temperature incrementally increased over $450 \mathrm{~m}$ from the forest edge towards the interior forest of the edge habitat, and the population density was lower at the edge site. Activity budgets differed between groups living in the two microhabitats, with individuals living near the edge spending more time travelling and less time feeding. Groups living near the edge also tended to have smaller home ranges and core areas than groups in the forest interior. In addition, edge groups had elevated average fGCM concentrations, and birth rates were lower for females living in the edge habitat. Combined with lower levels of fruit consumption at the edge, these results suggest that nutritional stress might be a limiting factor for Verreaux's sifakas when living near a forest edge. Hence, Verreaux's sifakas appear to be sensitive to microhabitat characteristics linked to forest edges; a result with implications for the conservation of this critically endangered lemurid species.
\end{abstract}

\section{Introduction}

Tropical forest habitats continue to become increasingly fragmented, thereby disintegrating populations and reducing suitable habitats for many species (Laurance, 1999; Watson et al., 2004). Fragmentation of habitats results in additional abrupt boundaries, creating so-called edge effects. Edge effects refer to how abiotic and biotic conditions interact between two adjacent habitats separated by an abrupt boundary, altering the distribution, abundance, and behaviour of organisms (Murcia, 1995). As environmental conditions, such as temperature, light intensity, plant growth, and level of distur- bance, change around edges, they can be considered as distinct ecosystems in comparison to undisturbed forest interiors (Laurance et al., 2000, 2011). Species responses towards edges are diverse (Lidicker, 1999): species that exhibit their highest densities at the edge are considered to show an edgepositive response, whereas species that avoid forest edges are considered to exhibit an edge-negative response, and species that show little or no response towards the edge are considered to be edge-neutral. Because species respond differently to living in edge habitats (Lehtinen et al., 2003; Lehman et al., 2006a, b; Delattre et al., 2009), studying edge effects is of key importance for species-specific conservation assessment. 
The effects of anthropogenic habitat changes are manyfold. First, numerous studies have demonstrated that disturbed environments are associated with elevated stress hormone, i.e. glucocorticoid (GC), levels in many vertebrate taxa, including primates (Dantzer et al., 2014). Specifically, in Yucatan spider monkeys (Ateles geoffroyi yucatanensis; Rangel-Negrín et al., 2009), brown spider monkeys (Ateles hybridus; Rimbach et al., 2013a), black howler monkeys (Alouatta pigra; Martínez-Mota et al., 2007; RangelNegrín et al., 2014), and grey-cheeked mangabeys (Lophocebus albigena; Jaimez et al., 2012) individuals living in disturbed and fragmented forests exhibited elevated GC levels compared with those inhabiting continuous and undisturbed forest patches. Collared brown lemur (Eulemur collaris) also exhibited elevated GC concentrations in degraded forests, where reduced fruit availability exacerbated the ecological challenges faced by these lemurs (Balestri et al., 2014). Hence, physiological stress responses to disturbed habitats are a major focus in conservation physiology because they provide a quantitative measure of how environmental changes impact individuals (Tarlow and Blumstein, 2007; Dantzer et al., 2014). Second, habitat fragmentation had a generally negative effect on the distribution of 32 lemur species (Eppley et al., 2020). Folivorous-frugivorous species, however, showed greater flexibility and variability in terms of habitat area and landscape complexity compared with nearly exclusively folivorous or frugivorous species, which appear to exhibit some resilience to forest fragmentation (Eppley et al., 2020). Third, population density and juvenile recruitment can depend on fragment size and the availability of key feeding trees, as shown for ring-tailed lemurs (Lemur catta; Gould and Cowen, 2020). Finally, habitat fragmentation may eventually also reduce genetic diversity, as shown in species such as the black-and-white ruffed lemurs (Varecia variegata: Baden et al., 2019) and goldenbrown mouse lemurs (Microcebus ravelobensis; Radespiel et al., 2019), leading to increased vulnerability due to stochastic demographic changes and potential bottlenecks.

As a biodiversity hotspot, Madagascar suffers from an alarming rate of habitat conversion and fragmentation (Harper et al., 2007; Schwitzer et al., 2014; Vieilledent et al., 2018). Madagascar has lost $44 \%$ of its natural forest cover over the 1953-2014 period (including 37\% over the 19732014 period; Vieilledent et al., 2018). Anthropogenic influences and habitat disturbance also have vital consequences for the endemic primates of Madagascar (Lemuriformes), which are considered to be the most endangered group of mammals today (Schwitzer et al., 2014). Some lemurs exhibit a negative edge response, such as Cheirogaleus major (Lehman et al., 2006a-c) and M. ravelobensis (Andriatsitohaina et al., 2019), but others have been found to exhibit a neutral (Eulemur rubriventer, Hapalemur griseus, and Avahi laniger) or even positive edge response (Microcebus rufus and Propithecus edwardsi), stressing the importance of studies of individual species or populations.
Among sifakas (genus Propithecus: Indridae), which are folivorous and, hence, potentially less resilient to habitat fragmentation (Eppley et al., 2020), responses to edges differ between species. Coquerel's sifakas (Propithecus coquereli) seem to avoid edge areas and do not range right on the forest edge but within $400 \mathrm{~m}$ of it, resulting in larger home ranges in comparison with groups occurring in the forest interior, although food quality does not differ between habitats (McGoogan et al., 2009). Diademed sifakas (Propithecus diadema) that live in forest fragments have smaller home ranges and appear to avoid feeding at fragment edges in contrast to groups living in the forest interior (Irwin, 2008). Subsequent blood analyses revealed a negative edge response on the physiological health of these animals as reflected by lower values of white blood cell counts, total protein, or iron-binding capacity (Irwin et al., 2010). Moreover, morphological traits of Diademed sifakas were affected by habitat quality, with individuals living in smaller fragments with low habitat quality exhibiting "wasting effects" in adults and "stunting effects" in juveniles (Irwin et al., 2019).

Given the interspecific variation in terms of behavioural and physiological effects to living in an edge habitat, the objective of this study was to investigate how forest edge habitats influence behavioural patterns, feeding ecology, and physiological stress hormone output in Verreaux's sifakas (Propithecus verreauxi), which were recently classified as "Critically Endangered" (IUCN, 2020). To this end, we studied three groups of sifakas inhabiting the interior of an intact forest area and two groups living at the forest edge along a savannah (Rakotoniaina et al., 2016). To determine whether Verreaux's sifakas respond to the associated differences in habitat structure, we collected data on ambient temperature, home range size, activity budgets, diet, faecal glucocorticoid metabolite output, and reproductive rates, and we compared these variables between the two populations.

\section{Methods}

\subsection{Study site and subjects}

This study was conducted at the German Primate Center (DPZ) field station in Kirindy Forest $\left(44^{\circ} 39^{\prime} \mathrm{E}, 20^{\circ} 04^{\prime} \mathrm{S}\right)$ in central western Madagascar. Data were collected from April to July 2012, which corresponds to the transition from the local wet (November-April) to dry (May-October) season. Most trees shed their leaves over the dry season, reducing food availability of the predominantly folivorous sifakas (Koch et al., 2017). The local study areas were situated about $2 \mathrm{~km}$ from each other: one in the forest interior and one bordering a treeless savannah that has been present for at least several decades (Rakotoniaina et al., 2016). We studied five groups with a total number of 20 individuals: three groups inhabited the forest interior and two groups lived at the forest edge close to the savannah (Table 1). Both study areas were 
fitted with a grid system of small foot trails (Kappeler and Fichtel, 2012).

Verreaux's sifakas are diurnal, arboreal, and live in groups of 2-12 individuals (mean \pm SD: $6 \pm 2$ individuals; Kappeler and Fichtel, 2012), which occupy home ranges that can vary in size due to seasonality, habitat quality, or group size (Carrai and Lunardini, 1996; Benadi et al., 2008; Rudolph et al., 2020). In the interior of Kirindy Forest, home range sizes ranged between 5 and 10 ha (Benadi et al., 2008; Koch et al., 2016), but corresponding data were not previously available for the forest edge. All study subjects were well habituated to human observers and marked individually by unique nylon collars and one radio transmitter per group (Kappeler and Fichtel, 2012).

\subsection{Temperature measurement}

Ambient temperature was measured once per hour continuously throughout the study using iButtons (1-Wire/iButton DS1921G-F5; accuracy $\pm 1{ }^{\circ} \mathrm{C}$ ). Both study sites are equipped with a grid system with $50 \mathrm{~m} \times 50 \mathrm{~m}$ trails in the edge habitat and $25 \mathrm{~m} \times 25 \mathrm{~m}$ trails in the forest interior. At each site, 10 iButtons were placed at breast height on tree trunks, with a distance of $50 \mathrm{~m}$ between them, on a perpendicular line of the grid systems, and the forest edge (Fig. 2). In the savanna, the first iButton was placed at the border of the edge and the last iButton was placed $450 \mathrm{~m}$ westwards. In the forest interior, the first iButton was placed in the centre of the study area and the last iButton was placed $450 \mathrm{~m}$ westwards.

\subsection{Behavioural data collection}

Behaviour of sifakas was recorded using continuous focal sampling (Altmann, 1974) of $1 \mathrm{~h}$ duration of all adult individuals of a group, resulting in $252 \mathrm{~h}$ of focal animal data. Individuals were chosen as focal animals in a randomized but counterbalanced order throughout the day, and we observed all individuals equally often. Observed behavioural states were assigned to one of four categories: feeding $(\mathrm{F})$, social behaviour (S), travelling $(\mathrm{T})$, and resting $(\mathrm{R})$. The feeding category included searching, manipulating, and ingesting food items within a food patch (i.e. tree). To characterize dietary composition, we recorded the plant parts of every species that a focal individual fed on within a feeding bout for longer than $5 \mathrm{~min}$ (e.g. leaves, fruits, buds, or flowers; Benadi et al., 2008; Koch et al., 2017). In addition, the GPS position of the plant was noted, the species was identified, and feeding tree characteristics such as diameter at breast height (dbh), height, and crown diameter were recorded.

The social behaviour category included all interactions between individuals, including affiliation (duration of grooming and huddling), agonism (frequency of bites and threats), and affinity (approaches within $1 \mathrm{~m}$ ). The travelling category included all movements or changes in location of at least $5 \mathrm{~m}$ by jumping or climbing (Trillmich et al., 2004). Spending at least $30 \mathrm{~s}$ without engaging in any of the above activities (e.g. sitting, watching, autogrooming, or sleeping) was recorded as resting. To determine the home range sizes, the location of each group was additionally recorded by taking the GPS position (Garmin CS76) of the focal animal every $15 \mathrm{~min}$.

\subsection{Faecal sample collection and faecal glucocorticoid metabolite (fGCM) analysis}

To measure stress hormone output via the determination of faecal glucocorticoid metabolite (fGCM) concentrations, three faecal samples per focal individual were collected between 8:00 and 10:00 UTC $+3(N=43$ except seven samples that were collect between 13:00 and 14:00 UTC+3) in three different sampling sessions every 2 weeks (mean \pm SD: $13 \pm 2$ d) from mid-May to the end of June. Each sample consisted of exactly five faecal droplets (in total $0.5-2.2 \mathrm{~g}$ fresh weight) that were collected immediately after defaecation and directly transferred into labelled polypropylene tubes containing $8 \mathrm{~mL}$ of $80 \%$ watery ethanol. Faeces where urine contamination was suspected were not sampled. All samples were extracted on-site on the day of sample collection, using a validated method for extracting faecal hormone metabolites under field conditions (Shutt et al., 2012).

Briefly, each sample was homogenized in its original ethanolic solvent using a metal rod, and the resulting faecal suspensions were subsequently vortexed for $2 \mathrm{~min}$ ( $\mathrm{Lab}$ Dancer S40). Samples were finally centrifuged for $2 \mathrm{~min}$ using a manually operated centrifuge. About $1 \mathrm{~mL}$ of the supernatant was decanted into a labelled $2 \mathrm{~mL}$ polypropylene tube, sealed with PARAFILM, and stored in the dark at ambient temperature until transport to the endocrinology laboratory of the German Primate Center within 3 weeks of the end of sample collection. Thus, sample extracts were stored in the field for a maximum of 4-5 months, a period during which fGCM concentrations have been shown to remain stable (Shutt et al., 2012; Rimbach et al., 2013b; Kalbitzer and Heistermann, 2013).

After arrival at the laboratory, samples were placed in a $-20{ }^{\circ} \mathrm{C}$ freezer and analysed for glucocorticoid metabolites within 2 weeks. Faecal extracts were analysed using an enzyme immunoassay for $11 \beta$-hydroxyetiocholanolone, a group-specific assay for the measurement of cortisol metabolites with a $3 \alpha, 11 \beta$-dihydroxy structure. The assay has previously been validated for monitoring glucocorticoid output in numerous species of primates (e.g. Heistermann et al., 2006), including Verreaux's sifakas (Fichtel et al., 2007). The assay was carried out as described in detail by Heistermann et al. (2004). Prior to assaying, all samples were diluted $1: 400$ in assay buffer (0.04 M PBS, pH 7.2), and duplicate $50 \mu \mathrm{L}$ aliquots were taken to assay. Sensitivity of the assay at $90 \%$ binding was $0.6 \mathrm{pg}$. Intra- and inter-assay coefficients of variation of high- and low-value quality controls were $6.5 \%$ (high, $n=16$ ) and $8.4 \%$ (low, $n=16$ ) and 
Table 1. Composition of the five study groups at the two study sites (“f” denotes females, and "m" denotes males).

\begin{tabular}{llrccrr}
\hline Site & Group & Size & $\begin{array}{c}\text { Adult } \\
\text { females }\end{array}$ & $\begin{array}{c}\text { Adult } \\
\text { males }\end{array}$ & Subadults & Juveniles \\
\hline Edge & 2 & 2 & 1 & 1 & 0 & 0 \\
& 3 & 6 & 1 & 3 & $1(\mathrm{f})$ & $1(\mathrm{~m})$ \\
\hline Interior & $\mathrm{C}$ & 4 & 1 & 2 & $1(\mathrm{f})$ & 0 \\
& $\mathrm{G}$ & 4 & 1 & 2 & $1(\mathrm{f})$ & 0 \\
& $\mathrm{~L}$ & $3(4)$ & 1 & 1 & $1(\mathrm{~m})$ & $1(\mathrm{f}) \dagger$ \\
\hline
\end{tabular}

$\dagger$ represents that animals died or disappeared during the study.

$7.1 \%$ (high, $n=6$ ) and $12.5 \%$ (low, $n=6$ ) respectively. All hormone concentrations are expressed as mass hormone per faecal mass (i.e. wet weight).

\subsection{Data analyses}

Differences in temperature between sites were estimated by fitting three linear mixed models (LMMs; Baayen, 2008) with either minimum, mean, or maximum temperature as response, site as fixed factor, and iButton ID as random factor. The influence of the distance to the edge border on temperature was estimated with three LMMs with either minimum, mean, or maximum temperature as response, distance of the iButton location to the edge border as fixed factor, and iButton ID as random factor. The models were fitted in $\mathrm{R}$ ( $\mathrm{R}$ Core Team, 2015) using the $1 \mathrm{~m}$ function of the "Ime4" R package (Bates et al., 2015).

Differences in time (rates per hour) spent travelling, feeding, resting, and interacting socially as well as time spent feeding on leaves, fruits, flowers, buds, and seeds between individuals occurring at the edge or interior forest were compared with a Mann-Whitney $U$ test using Past3, as these data were not normally distributed.

ArcView (version 3.3) was used to calculate the home ranges of the study groups based on minimum convex polygons (MCPs). Adaptive kernel analyses were also used to calculate home ranges at $95 \%$ of raster resolution and at $50 \%$ for the core areas, using an automatically selected LCSV smoothing parameter (Burgman and Fox, 2003).

To test whether fGCM levels were influenced by study site (i.e. forest interior vs. edge habitat), we used a linear mixed model (Baayen, 2008) into which we included median fGCM levels as response, site as a fixed effect, and sex as control factor because some females were gestating. The model was fitted in R ( $\mathrm{R}$ Core Team, 2015) using the $\mathrm{lm}$ function of the lme4 R package (version 3.3.2; Bates et al., 2015).

Groups in both habitats (edge: $N_{\text {groups }}=3$; forest interior: $N_{\text {groups }}=9$ ) are part of a long-term project in which group compositions including births have been assessed during regular census visits (Kappeler and Fichtel, 2012). Originally there were three groups of sifakas at the forest edge, but one group dissolved in 2011. To estimate differences in birth rates, we assessed whether each female (edge: $N_{\text {females }}=4$; forest interior: $N_{\text {females }}=12$ ) of each group gave birth (yes or no) between 2009 and 2013. We fitted a generalized linear mixed model (GLMM; Zuur et al., 2009) using the lme4 package (Bates et al., 2015) by including a binomial response term indicating whether or not a female gave birth in a given year and site as fixed factors as well as mother ID and year as random factors.

In general, after fitting each model, we checked the assumptions regarding the normality of distributions and homoscedasticity and compared the full model to a null model, including the control factor, using maximum likelihood ratio tests.

\subsection{Ethical statement}

This study was approved and authorized by the CAFF/CORE of the Direction des Eaux et Forêts Madagascar and the CNFEREF Morondava, Madagascar. Verreaux's sifakas (Propithecus verreauxi) are currently classified as critically endangered (IUCN, 2020).

\section{Results}

\subsection{Sifaka densities}

The study area at the edge comprised 31 ha and was inhabited by two groups consisting of six Verreaux's sifakas, whereas the study area in the forest interior comprised 70 ha and housed nine groups consisting of 44 individuals, indicating a lower population density in the edge habitat.

\subsection{Ambient temperatures}

Daily minimum, mean, or maximum temperatures did not differ between study sites (Fig. 2a-c; Table 2a-c). Daily mean temperatures decreased with incremental distance from the border of the edge towards the interior of the forest (Fig. 3, Table 2e). However, daily minimum and maximum temperatures did not change over distance (Table $2 \mathrm{~d}, \mathrm{f}$ ). 
Table 2. Parameter estimates from the linear mixed model (LMM) fitting differences in minimum, mean, and maximum temperature between study sites $(\mathrm{a}-\mathrm{c})$ and as a function of the distance to the edge border $(\mathrm{d}-\mathrm{f})$ with corresponding full-null model comparisons.

\begin{tabular}{llrrr}
\hline Response variable & Fixed factor & Estimate & SE & $p$ value \\
\hline (a) Minimum temperature & Intercept & 14.26 & 0.16 & $<0.001$ \\
\cline { 2 - 5 } & Site & -0.22 & 0.22 & 0.337 \\
\hline
\end{tabular}

Full-null model comparison: $\chi^{2}=1.05, \mathrm{~d} f=1, p=0.305$

\begin{tabular}{llrrr}
\hline (b) Mean temperature & Intercept & 22.18 & 0.18 & $<0.001$ \\
\cline { 2 - 5 } & Site & -0.5 & 0.26 & 0.071 \\
\hline Full-null model comparison: & $\chi^{2}=3.72, \mathrm{~d} f=1, p=0.054$ & \\
\hline (c) Maximum temperature & Intercept & 33.44 & 0.54 & $<0.001$ \\
\cline { 2 - 5 } & Site & -1.28 & 0.76 & 0.108 \\
\hline Full-null model comparison: & $\chi^{2}=2.95, \mathrm{~d} f=1, p=0.086$ & \\
\hline (d) Minimum temperature & Intercept & 14.67 & 0.23 & $<0.001$ \\
\cline { 2 - 5 } & Distance & -0.002 & 0.001 & 0.066 \\
\hline Full-null model comparison: & $\chi^{2}=4.45, \mathrm{~d} f=1, p=0.035$ & \\
\hline (e) Mean temperature & Intercept & 23.1 & 0.22 & $<0.001$ \\
\cline { 2 - 5 } & Distance & -0.004 & 0.001 & 0.001 \\
\hline Full-null model comparison: & $\chi^{2}=13.932, \mathrm{~d} f=1, p<0.001$ & \\
\hline (f) Maximum temperature & Intercept & 34.89 & 1.32 & $<0.001$ \\
\cline { 2 - 5 } & Distance & -0.01 & 0.01 & 0.227 \\
\hline Full-null model comparison: & $\chi^{2}=1.94, \mathrm{~d} f=1, p=0.164$ & \\
\hline
\end{tabular}

\subsection{Home ranges}

Home ranges varied in size between groups occurring at the edge and forest interior (Fig. 1; Table 3). Based on kernel analyses with $95 \%$ and $50 \%$ of raster resolution, groups at the edge had smaller home ranges (K95\%: 2.9, $3.1 \mathrm{ha}$; $\mathrm{K} 50 \%: 0.3,0.1 \mathrm{ha}$ ) than groups in the forest interior (K95\%: 9.0, 9.8, 3.6 ha; K50\%: 02.9, 3.1 ha). Based on MCPs, only two groups in the interior had larger home ranges $(9.4,8.2$, $4.7 \mathrm{ha}$ ) than the two groups at the edge (2.8 and $4.7 \mathrm{ha})$, and one group in each habitat type had about the same home range size.

\subsection{Activity budgets}

Sifakas near the forest edge spent less time feeding (Fig. 4a; Mann-Whitney $U$ test, $U=8, p=0.045$ ) but more time travelling than sifakas inhabiting the forest interior (Fig. 4b; Mann-Whitney $U$ test, $U=0, p=0.002$ ). However, the two populations did not differ with respect to average time spent socializing or resting (Fig. 4c, d; Mann-Whitney $U$ test: socializing: $U=11, p=0.107$; resting: $U=14, p=0.22$ ).

\subsection{Consumed feeding plants}

In total, sifakas consumed leaves, fruits, flowers, buds, and seeds of 45 different plant species (edge: 22 species; interior: 32 species). Sifakas at the forest edge fed on all items, whereas sifakas in the forest interior fed mainly on leaves, fruits, and flowers; however, the average feeding times on these food items did not differ significantly between populations (Fig. 5a, b, c; Mann-Whitney $U$ test: leaves: $U=$ $12, p=0.138$; buds: $U=14.5, p=0.244$; seeds: $U=16$, $p=0.112$ ). However, sifakas in the interior spent more time feeding on fruits, whereas sifakas at the edge spent more time feeding on flowers (Fig. 5c, d; Mann-Whitney $U$ test: fruits: $U=5, p=0.017$; flowers: $U=9, p=0.029$ ).

The five most often consumed species varied between the two populations, with sifakas at the edge consuming primarily Namologna (Foetidia retusa) and Alimboro (Albizia bernieri), whereas sifakas in the forest interior consumed primarily Manjakabenitany (Baudouinia fluggeiformis) and Anakaraky (Dupuya madagascariensis). Feeding tree characteristics, such as dbh, tree height, and crown diameter, did not differ between study sites (Mann-Whitney $U$ test: dbh: $p=0.21$; height: $p=0.08$; crown diameter: $p=0.13$ ). 


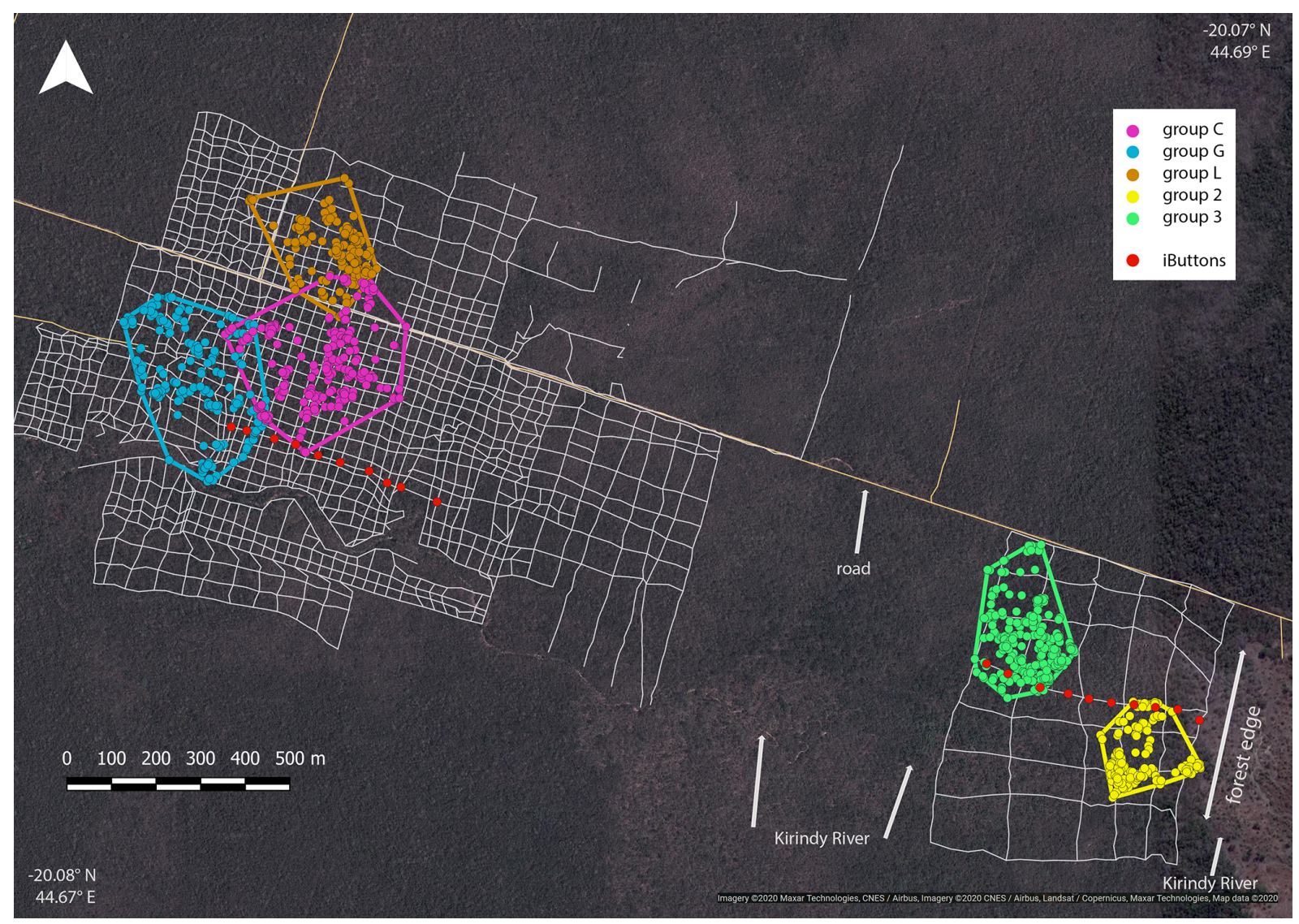

Figure 1. Satellite image of the study area depicting the home ranges of the study groups in the interior (groups $\mathrm{C}, \mathrm{G}$ and $\mathrm{L}$ ) and at the edge (groups 2 and 3) with MCPs (minimum convex polygons), the grid system of small foot trails (grey lines), and iButton locations (red dots). Imagery (C) 2020 Maxar Technologies, CNES/Airbus, Imagery @ C 2020/CNES/Airbus, Landsat/Copernicus, Maxar Technologies, Map data (C) 2020 .
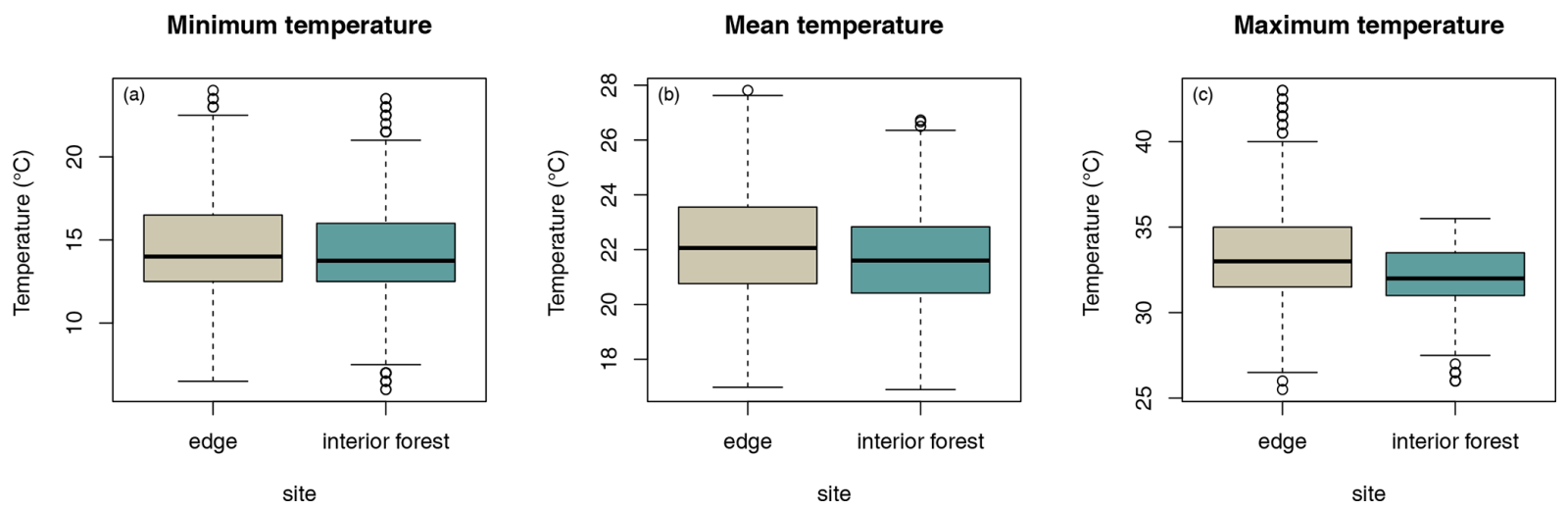

Figure 2. Differences in daily (a) minimum, (b) mean, and (c) maximum temperatures between sites.

\subsection{Variation in fGCM concentrations}

Sifakas at the edge had higher average fGCM concentrations than those inhabiting the forest interior (Fig. 6; LMM, fullnull model comparison: $\chi^{2}=5.59, \mathrm{~d} f=1, p=0.038$; site: estimate \pm SE: $-212.43 \pm 89.83, p=0.038$; sex: estimate \pm SE: $-97.58 \pm 92.78, p=0.316)$.

\subsection{Reproductive rates}

In both habitats, each group included only one adult female. Of the two females in the edge population, only one gave birth, whereas in the three groups living in the forest interior, all females gave birth a month after the completion of this study. To compare reproductive rates, we analysed additional 
Table 3. Results of the home range estimates of each group based on different methods.

\begin{tabular}{llrrcccc}
\hline Site & Group & $\begin{array}{r}\text { Group } \\
\text { size }\end{array}$ & $\begin{array}{c}\text { GPS } \\
\text { points }\end{array}$ & $\begin{array}{c}\text { MCPs } \\
\text { (ha) }\end{array}$ & $\begin{array}{c}\text { K 95\% } \\
\text { (ha) }\end{array}$ & $\begin{array}{c}\text { Core area, } \\
\text { K 50\% (ha) }\end{array}$ & $\begin{array}{c}\text { Intergroup } \\
\text { encounters }\end{array}$ \\
\hline Edge & 2 & 2 & 144 & 2.8 & 2.9 & 0.3 & 8 \\
& 3 & 6 & 287 & 4.7 & 3.1 & 0.1 & 1 \\
\hline \multirow{2}{*}{ Interior } & $\mathrm{C}$ & 4 & 216 & 9.4 & 9.0 & 2.0 & 4 \\
& $\mathrm{G}$ & 4 & 216 & 8.2 & 9.8 & 1.6 & 0 \\
& $\mathrm{~L}$ & $3(4)$ & 152 & 4.7 & 3.6 & 0.4 & 1 \\
\hline
\end{tabular}

MCPs denotes minimum convex polygons, and $\mathrm{K}$ denotes kernel analysis.

\section{Mean temperature}

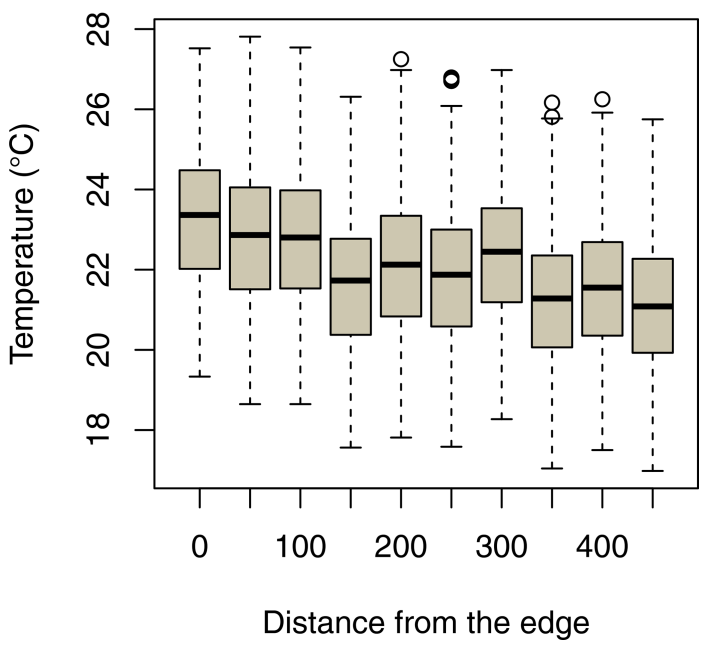

Figure 3. Decrease in daily mean temperatures as a function of the distance of iButton locations from the border of the forest edge.

demographic data from 4 females from three different groups at the edge and 12 females from nine different groups in the interior. Sifakas near the edge had significantly lower birth rates compared with those living in the forest interior. Based on 45 infants born at both sites between 2009 and 2013, the average birth rate per female was 0.31 infants per year at the edge and 0.78 infants per year in the interior. The probability that a female gave birth was influenced by site but not by year (Fig. 7; GLMM, full-null model comparison: $\chi^{2}=11.77$, $\mathrm{d} f=1, p<0.001$; site: estimate $\pm \mathrm{SE}:-2.08 \pm 0.643, p=$ 0.001 ).

\section{Discussion}

The results of this study indicate that Verreaux's sifakas may respond behaviourally and physiologically to habitat variation related to the forest edge, which differs with respect to forest structure (Rakotoniaina et al., 2016) and average temperatures close to the border of the edge but not with respect to crude measures of feeding tree characteristics. Sifakas liv- ing in the edge habitat appeared to have lower population densities and smaller home ranges, but they spent more time travelling. In addition, they spent less time feeding but did not differ from the interior groups regarding time spent socializing and resting. Both populations had broadly similar diets, but only sifakas in the edge habitats consumed seeds and fed less often on fruits but more often on flowers. These behavioural differences appear to be biologically meaningful because sifakas living near the forest edge had elevated fGCM concentrations and lower birth rates. Altogether, these preliminary results based on a small sample size suggest that Verreaux's sifakas in Kirindy Forest may exhibit a negative edge response.

The microclimate in the edge habitat in Kirindy Forest did not differ with respect to daily temperatures from the forest interior, but it exhibited higher daily mean temperatures directly at the border of the habitat. The edge habitat was, similarly to other edge habitats in Madagascar, characterized by a lower tree density (Lehtinen et al., 2003; Lehman et al., 2006a-c; Rakotoniaina et al., 2016). Despite the lower tree density, both habitats exhibit broadly similar additional characteristics, including traversal by a river and a dirt road. However, sifakas at the edge inhabited substantially smaller home ranges than groups in the interior; in fact, they represent the smallest known home ranges of Verreaux's sifakas (Carrai and Lunardini, 1996; Richard, 1978; Benadi et al., 2008; Koch et al., 2016). Moreover, home ranges of groups in the interior forest overlapped among groups, whereas in the edge habitat, the two groups were separated by an area that was not occupied by sifakas. Whereas two groups of sifakas in the forest interior regularly crossed the dirt road, the home ranges of the groups living at the forest edge did not include the dirt road, and the home range of one group at either site bordered on the riverbed (Fig. 1). Therefore, we believe that potential effects derived from the dirt road and/or the river are minor at best with respect to causing the inter-site behavioural and physiological differences seen between the populations. Further, without data on habitat quality within home ranges, it is difficult to assess potential difference between the populations, but the higher travelling activity and fGCM levels indicate that the edge habitat might 

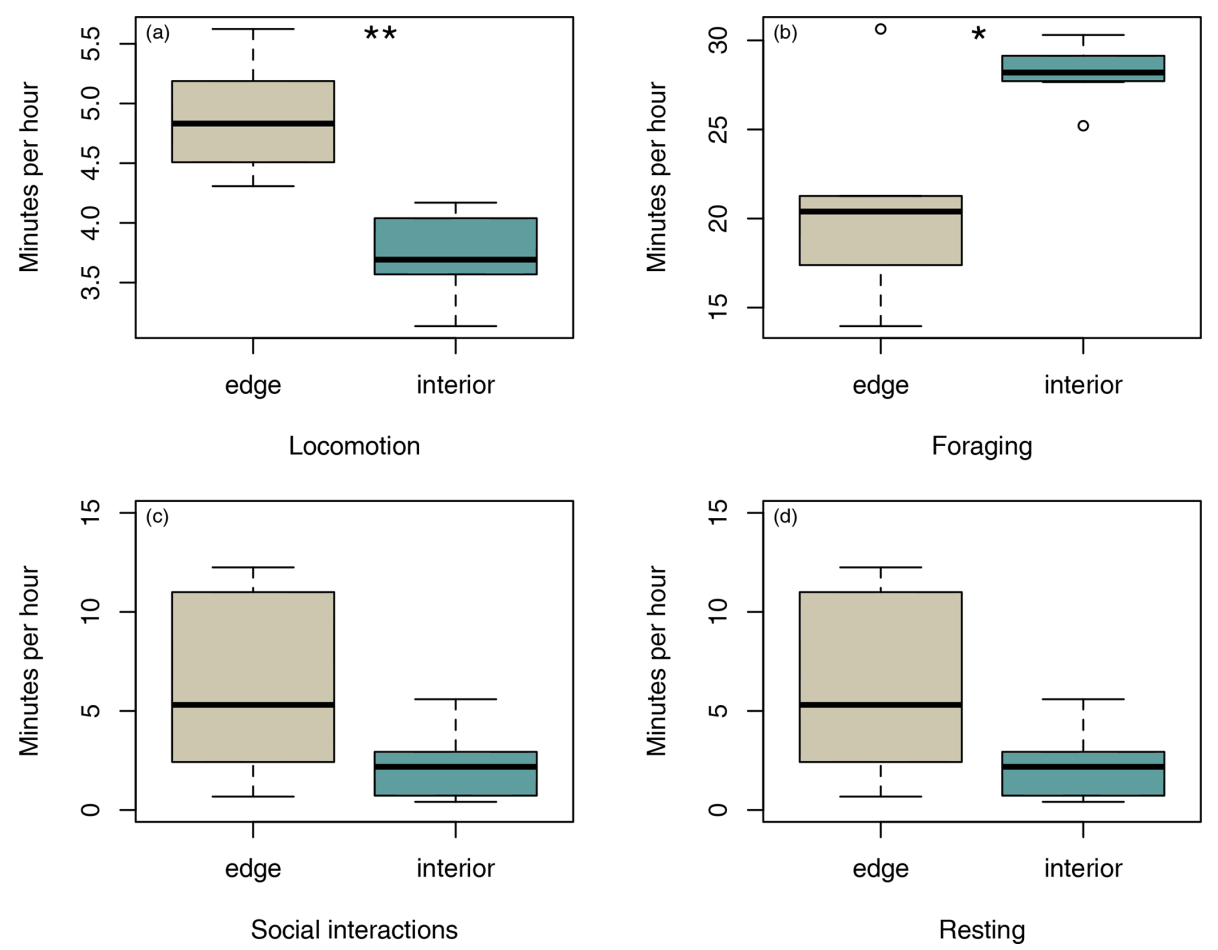

Figure 4. Differences in average duration of (a) locomotion, (b) foraging, (c) social interactions, and (d) resting between groups at the two study sites. Depicted are medians (black horizontal lines), interquartile ranges (boxes), and outliers (circles).
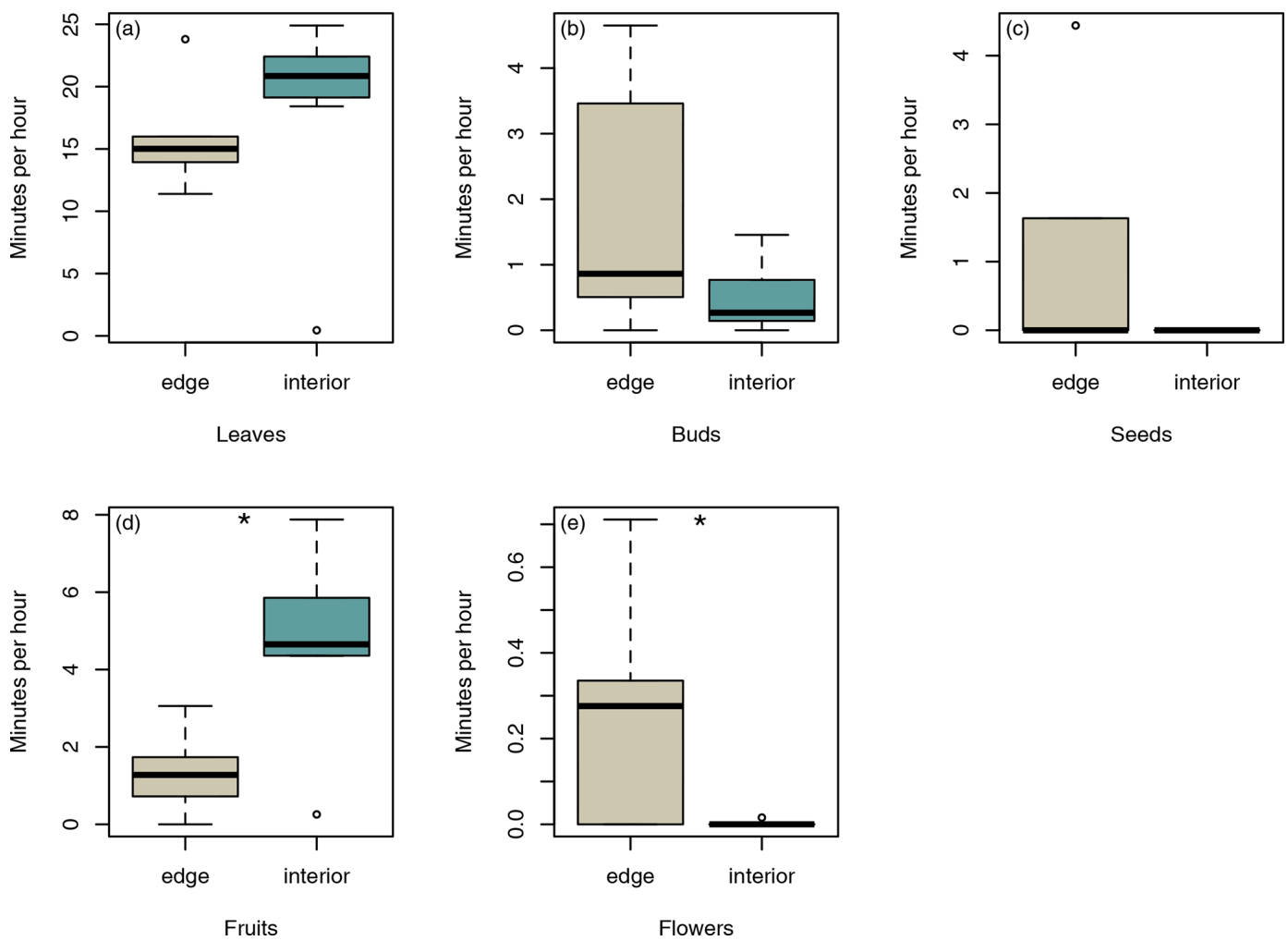

Figure 5. Differences in average time spent feeding on (a) leaves, (b) buds, (c) seeds, (d) fruits, and (e) flowers. Depicted are medians (black horizontal lines), interquartile ranges (boxes), and outliers (circles). 


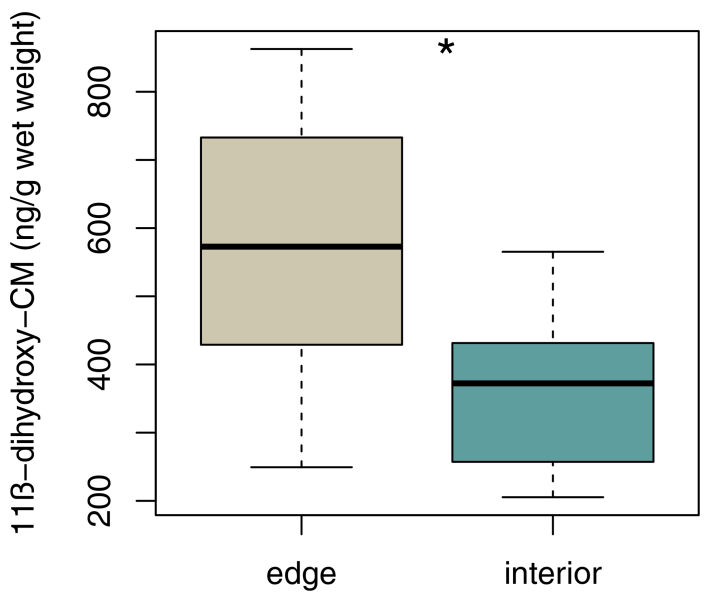

site

Figure 6. Median faecal glucocorticoid metabolite concentrations for each study site. Depicted are medians (black horizontal lines) and interquartile ranges (boxes).

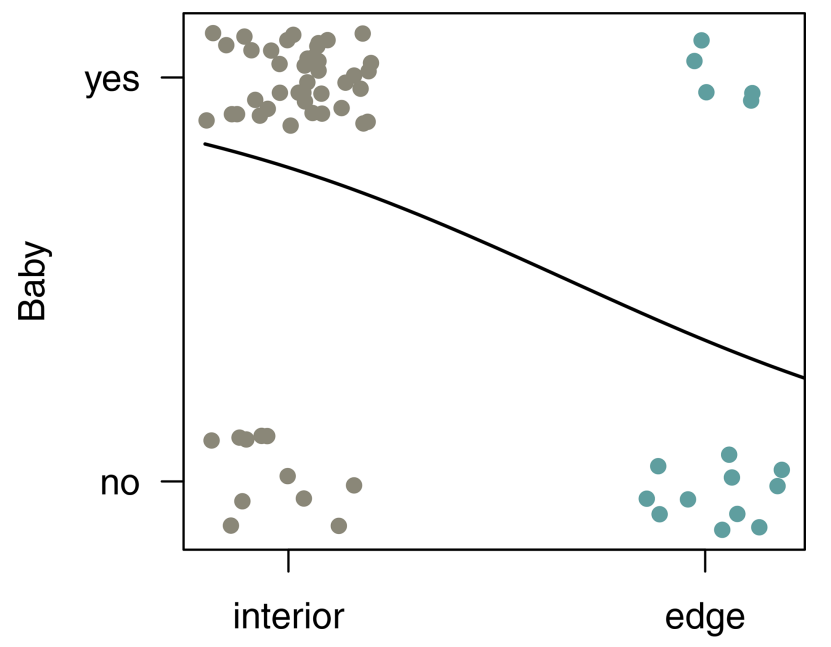

site

Figure 7. Probability (yes or no) of giving birth for females living in the edge or forest interior habitat.

have been of lesser quality, despite the potential benefit of additional light and plant productivity (Ganzhorn, 1992).

Interestingly, the closely related Coquerel's sifakas in dry deciduous forests in Ankarafantsika National Park exhibited the opposite pattern, with edge groups inhabiting larger home ranges than groups in the forest interior (McGoogan et al., 2009). Activity budgets and food quality did not differ between those habitats, but larger home ranges of edge groups might have been due to the fact that these Coquerel's sifakas did not use the immediate forest edge and instead roamed about $400 \mathrm{~m}$ away from it. Similar, Diademed sifakas in fragmented habitats avoided the edges, whereas those in continu- ous forests did not avoid the edge (Irwin, 2008). In our study, where the edge presents a naturally derived edge, one group of Verreaux's sifakas inhabited a home range that encompassed the border of the edge and, hence, did not appear to avoid the edge.

The five most commonly consumed feeding trees of sifakas did not differ in size between sites, and both populations had broadly similar diets. Groups in the forest interior, however, spent more time feeding on fruits, whereas edge groups spent more time feeding on seeds and flowers, which are more quickly ingested than fruits and may require higher rates of switches between feeding sites (Norscia et al., 2006; Irwin, 2008; Gabriel, 2013). This fact may explain why edgeliving sifakas spent more time travelling than individuals in the forest interior. As we only have phenology data for the interior forest, we cannot evaluate whether there were generally fewer fruiting trees present in the edge habitat. The presence of the Kirindy River, which runs through both habitats, however, should have a similar impact on tree phenology at both sites.

Nevertheless, the higher fruit feeding rates of the interior groups may suggest that they may have enjoyed a higher energy intake. Reduced energy intake via reduced fruit consumption is often associated with an increase in glucocorticoid output, indicating nutritional stress (Creel et al., 2002; Homan et al., 2003; Pride, 2005; Dunn et al., 2013). In chimpanzees (Pan troglodytes), for example, urinary cortisol levels have been found to increase when they feed less on fruits (Muller and Wrangham, 2004). Similarly, fGCM levels have been reported to be negatively correlated with habitat quality in Diademed sifakas ( $P$. diadema) as well as in both Diademed and Verreaux's sifakas during periods of fruit scarcity (Tecot et al., 2019; Rudolph et al., 2020). Moreover, energetically costly travelling rates are associated with an increase in fGCM levels in mantled howler monkeys (Alouatta palliata; Gómez-Espinosa et al., 2014). However, daily travel distances and variation in home range size did not affect fGCM levels in Verreaux's sifakas living in the forest interior (Rudolph et al., 2019). Hence, increased fGCM levels found in the present study might be due to the lower energy intake, i.e. the lower rate of fruit consumption, by sifakas inhabiting the edge habitat.

In contrast to faecal glucocorticoid measurements, hair cortisol measurements integrate changes in glucocorticoid output over periods of weeks and months and may provide information on chronically increased stress hormone levels. Squirrel gliders (Petaurus norfolcensis) have been found to exhibit higher hair cortisol levels in urbanized edges than in intact habitats (Brearley et al., 2012). However, edge-positive grey mouse lemurs (Microcebus murinus) and edge-negative fat-tailed dwarf lemurs (Cheirogaleus medius), which were studied in the same edge and interior forest habitat as in our study, did not differ in hair cortisol levels and parasite burden (Rakotoniaina et al., 2016). As glucocorticoid concentrations in sifakas in our study were measured in faecal samples re- 
flecting stress hormone output over a shorter timescale (Fichtel et al., 2007), our fGCM measure might more likely reflect a response to short-term variation in diet rather than a general adaptation to living in the edge habitat. Hence, measurements of sifaka hair cortisol are required to confirm this assumption. In this respect, in eastern chipmunks (Tamias striatus) individuals from logged habitats have been found to have higher faecal glucocorticoid metabolite levels than individuals from intact habitats, but hair cortisol levels did not differ between these groups (Mastromonaco et al., 2014). As chipmunks could easily move between logged and undisturbed areas and faecal samples were collected from the periphery of the logged area, the increase in faecal glucocorticoid metabolite levels might rather reflect short-term increases in cortisol, whereas the similar hair cortisol levels of individuals in both areas may indicate that habitat disturbance may not have affected long-term stress hormone output. Hence, depending on the glucocorticoid measure taken, i.e. from faeces or hair, the temporal scale of the sample collection should be taken into account (Mastromonaco et al., 2014).

At the ultimate level, elevated glucocorticoid concentrations are often associated with impairment of gonadal function and reproductive behaviour in female and male vertebrates (Cameron, 1997; Hardy et al., 2005) and are linked to reduced reproductive output in a variety of species (e.g. Ellenberg et al., 2007; Buck et al., 2007; Dantzer et al., 2014; Vitousek et al., 2018). For example, in northern sawwhet owl (Aegolius acadicus) habitat loss and fragmentation increased physiological stress levels in males and resulted in lower reproductive success (Hinam and St. Clair, 2008). Here, our data suggest that such a link between elevated glucocorticoid levels and decreased reproductive success may also exist for edge-living Verreaux's sifakas, which, according to our long-term records, show significantly reduced birth rates when compared with sifakas living in the forest interior. However, the small number of animals studied for stress hormone output and the fact that our faecal measure of glucocorticoid output may not fully reflect the effect of longterm stress precludes us from drawing firm conclusions. Future studies including more animals possibly in other edgehabitat locations and GCM analyses from faeces over a more extended period or even cortisol analyses from hair should be carried out to substantiate our preliminary reasoning. These future studies may also try to collect comparative data on female ovarian activity for assessing ovulation and conception rates, reproductive behaviour, and possibly energetic condition to help uncover the possible mechanisms underlying a potential link between stress hormone output and reproductive function and success in Verreaux's sifaka populations living in different habitat types. This, in turn, may help improve the conservation efforts for this highly endangered primate species.

\section{Conclusions}

Although Verreaux's sifakas in Kirindy survive and reproduce in the edge habitat, they appear to be sensitive to variation in microhabitat conditions that may be linked to the forest edge. However, more information on habitat characteristics in the edge and interior forest is required to test this notion. As the forest cover in the Kirindy Forest region continues to decline (Zinner et al., 2014), and habitat fragmentation into smaller forest patches leads to a decrease in the interiorto-edge ratio, the results of this study - indicating that Verreaux's sifakas might show a negative edge response - offer relevant information for future assessments of the conservation status of this species.

Data availability. Data are available in the Supplement.

Supplement. The supplement related to this article is available online at: https://doi.org/10.5194/pb-8-1-2021-supplement.

Author contributions. $\mathrm{KD}$ and $\mathrm{CF}$ conceived the study and analysed the data. KD collected behavioural data and faecal samples. $\mathrm{MH}$ supervised the hormone analysis. $\mathrm{KD}, \mathrm{CF}, \mathrm{MH}$, and PMK wrote the paper.

Competing interests. The authors declare that they have no conflict of interest.

Acknowledgements. We thank the Département de Biologie Animale, Université d'Antananarivo; the CAFF/CORE of the Direction des Eaux et Forêts; and the CNFEREF Morondava for the authorization of this study. We are extremely thankful to the DPZ staff at Kirindy and Morondava for support and companionship in the field. Special thanks go to Remy d'Ampataka, Tianasoa Andrianjanahary, and Jean-Pierre Tolojanahary for their support in the field and to Andrea Heistermann for technical assistance with the hormone analysis.

Financial support. This research has been supported by a grant from the "Ethologische Gesellschaft" to Klara Dinter.

Review statement. This paper was edited by Ute Radespiel and reviewed by two anonymous referees. 


\section{References}

Altmann, J.: Observational study of behavior: sampling methods, Behaviour, 49, 227-67, 1974.

Andriatsitohaina, B., Ramsay, M. S., Kiene, F., Lehman, S. M., Rasoloharijaona, S., Rakotondravony, R., and Radespiel, U.: Ecological fragmentation effects in mouse lemurs and small mammals in northwestern Madagascar, Am. J. Primatol., e23059, https://doi.org/10.1002/ajp.23059, 2019.

Baayen, R. H.: Analyzing linguistic data: A practical introduction to statistics using R, Cambridge University Press, Cambridge, UK, 2008.

Baden, A. L., Mancini, A. N., Federman, S., Holmes, S. M., Johnson, S. E., Kamilar, J., Louis Jr., E. E., and Bradley, B. J.: Anthropogenic pressures drive population genetic structuring across a critically endangered lemur species range, Sci. Rep.-UK, 9, 16276, https://doi.org/10.1038/s41598-019-52689-2, 2019.

Balestri, M., Barresi, M., Campera, M., Serra, V., Ramanamanjato, J. B., Heistermann, M., and Donati, G.: Habitat degradation and seasonality affect physiological stress levels of Eulemur collaris in littoral forest fragments, PloS One, 9, e107698, https://doi.org/10.1371/journal.pone.0107698, 2014.

Bates, D., Maechler, M., Bolker, B., and Walker, S.: Fitting linear mixed-effects models using lme4, J. Stat. Softw., 67, 1-48, 2015.

Benadi, G., Fichtel, C., and Kappeler, P. M.: Intergroup relations and home range use in Verreaux's Sifaka (Propithecus verreauxi), Am. J. Primatol., 70, 956-965, 2008.

Brearley, G., McAlpine, C., Bell, S., and Bradley, A.: Influence of urban edges on stress in an arboreal mammal: a case study of squirrel gliders in southeast Queensland, Australia, Landscape Ecol., 27, 1407-1419, 2012.

Buck, C. L., O'Reilly, K. M., and Kildaw, S. D.: Interannual variability of Black-legged Kittiwake productivity is reflected in baseline plasma corticosterone, Gen. Comp. Endocr., 150, 430 436, 2007.

Burgman, M. A. and Fox, J. C.: Bias in species range estimates from minimum convex polygons: implications for conservation and options for improved planning, Anim. Conserv., 6, 19-28, 2003.

Cameron, J. L.: Stress and behaviourally induced reproductive dysfunction in primates, Semin. Reprod. Endocr., 15, 37-45, 1997.

Carrai, V. and Lunardini, A.: Activity patterns and home range use of two groups of Propithecus v. verreauxi in the Kirindy Forest, Primate Report, 46, 275-284, 1996.

Creel, S., Fox, J. E., Hardy, A., Sands, J., Garrott, B., and Peterson, R. O.: Snowmobile activity and glucocorticoid stress responses in wolves and elk, Conserv. Biol., 16, 809-814, 2002.

Dantzer, B., Fletcher, Q. E., Boonstra, R., and Sheriff, M. J.: Measures of physiological stress: a transparent or opaque window into the status, management and conservation of species?, Conserv. Physiol., 2, cou023, https://doi.org/10.1093/conphys/cou023, 2014.

Delattre, P., Morellet, N., Codreanu, P., Miot, S., Quéré, J.-P., Sennedot, F., and Baudry, J.: Influence of edge effects on common vole population abundance in an agricultural landscape of eastern France, Acta Theriol., 54, 51-60, 2009.

Dunn, J. C., Cristóbal-Azkarate, J., Schulte-Herbrüggen, B., Chavira, R., and Veà, J. J.: Travel time predicts fecal glucocor- ticoid levels in free-ranging howlers (Alouatta palliata), Int. J. Primatol., 34, 246-259, 2013.

Ellenberg, U., Setiawan, A. N., Cree, A., Houston, D. M., and Seddon, P. J.: Elevated hormonal stress response and reduced reproductive output in Yellow-eyed penguins exposed to unregulated tourism, Gen. Comp. Endocr., 152, 54-63, 2007.

Eppley, T. M., Santini, L., Tinsman, J. C., and Donati, G.: Do functional traits offset the effects of fragmentation? The case of large-bodied diurnal lemur species, Am. J. Primatol., 82, e23104, https://doi.org/10.1002/ajp.23104, 2020.

Fichtel, C., Kraus, C., Ganswindt, A., and Heistermann, M.: Influence of reproductive season and rank on faecal glucocorticoid levels in free-ranging male Verreaux's sifakas (Propithecus verreauxi), Horm. Behav., 51, 640-648, 2007.

Gabriel, D. N.: Habitat use and activity patterns as an indication of fragment quality in a strepsirrhine primate, Int. J. Primatol., 34, 388-406, 2013.

Ganzhorn, J. U.: Leaf chemistry and the biomass of folivorous primates in tropical forests, Oecologia, 91, 540-547, 1992.

Gómez-Espinosa, E., Rangel-Negrín, A., Chavira, R., CanalesEspinosa, D., and Dias, P. A. D.: The effect of energetic and psychosocial stressors on glucocorticoids in mantled howler monkeys (Alouatta palliata), Am. J. Primatol., 76, 362-373, 2014.

Gould, L. and Cowen, L. L.: Lemur catta in small forest fragments: Which variables best predict population viability?, Am. J. Primatol., 82, e23095, https://doi.org/10.1002/ajp.23095, 2020.

Hardy, M. P., Gao, H., Dong, Q., Ge, R., Wang, Q., Chai, W. R., Feng, X., and Sottas, C.: Stress hormone and male reproductive function, Cell Tissue Res., 322, 147-153, 2005.

Harper, G. J., Steininger, M. K., Tucker, C. J., Juhn, D., and Hawkins, F.: Fifty years of deforestation and forest fragmentation in Madagascar, Environ. Conserv., 34, 1-9, 2007.

Heistermann, M., Ademmer, C. H. R., and Kaumanns, W.: Ovarian cycle and effect of social changes on adrenal and ovarian function in Pygatherix nemaeus, Int. J. Primatol., 25, 689-708, 2004.

Heistermann, M., Palme, R., and Ganswindt, A.: Comparison of different enzyme-immunoassays for assessment of adrenocortical activity in primates based on faecal analysis, Am. J. Primatol., 68, 257-273, 2006.

Hinam, H. L. and St. Clair, C. C. S.: High levels of habitat loss and fragmentation limit reproductive success by reducing home range size and provisioning rates of Northern saw-whet owls, Biol. Conserv., 141, 524-535, 2008.

Homan, R. N., Regosin, J. V., Rodrigues, D. M., Reed, J. M., Windmiller, B. S., and Romero, L. M.: Impacts of varying habitat quality on the physiological stress of spotted salamanders (Ambystoma maculatum), Anim. Conserv., 6, 11-18, 2003.

Irwin, M. T.: Diademed sifaka (Propithecus diadema) ranging and habitat use in continuous and fragmented forest: higher density by lower viability in fragments?, Biotropica, 40, 231-240, 2008.

Irwin, M. T., Junge, R. E., Raharison, J.-L., and Samonds, K. E.: Variation in physiological health of diademed sifakas across intact and fragmented forest at Tsinjoarivo, Eastern Madagascar, Am. J. Primatol., 72, 1013-1025, 2010.

Irwin, M. T., Samonds, K. E., Raharison, J. L., Junge, R. E., Mahefarisoa, K. L., Rasambainarivo, F., Godfrey, L. R., and Glander, K. E.: Morphometric signals of population decline in diademed sifakas occupying degraded rainforest habitat in Madagascar, Sci. Rep., 9, 1-14, 2019. 
IUCN: The IUCN Red List of Threatened Species, Version 2020-2, available at: https://www.iucnredlist.org, last access: 9 July 2020.

Jaimez, N. A., Bribiescas, R. G., Aronsen, G. P., Anestis, S. A., and Watts, D. P.: Urinary cortisol levels of gray-cheeked mangabeys are higher in disturbed compared to undisturbed forest areas in Kibale National Park, Uganda, Anim. Conserv., 15, 242-247, 2012.

Kalbitzer, U. and Heistermann, M.: Long-term storage effects in steroid metabolite extracts from baboon (Papio sp.) faeces - a comparison of three commonly applied storage methods, Methods Ecol. Evol., 4, 493-500, 2013.

Kappeler, P. M. and Fichtel, C.: A 15-year perspective on the social organization and life history of Sifaka in Kirindy Forest, in: Long-Term Field Studies of Primates, edited by: Kappeler, P. M. and Watts, D. P., Springer, Berlin and Heidelberg, Germany, 101121, 2012.

Koch, F., Signer, J., Kappeler, P. M., and Fichtel, C.: Intergroup encounters in Verreaux's sifakas (Propithecus verreauxi): who fights and why?, Behav. Ecol. Sociobiol., 70, 797-808, 2016.

Koch, F., Ganzhorn, J. U., Rothman, J. M., Chapman, C. A., and Fichtel, C.: Sex and seasonal differences in diet and nutrient intake in Verreaux's sifakas (Propithecus verreauxi), Am. J. Primatol., 79, e22595, https://doi.org/10.1002/ajp.22595, 2017.

Laurance, W. F.: Reflections on the tropical deforestation crisis, Biol. Conserv., 91, 109-117, 1999.

Laurance, W. F., Delamônica, P., Laurance, S., Delamônica, P., Laurance, S. G., Vasconcelos, H. L., and Thomas, E.: Rainforest fragmentation kills big trees, Nature, 404, 836, https://doi.org/10.1038/35009032, 2000.

Laurance, W. F., Camargo, J. L., Luizão, R. C., Laurance, S. G., Pimm, S. L., Bruna, E. M., and Van Houtan, K. S.: The fate of Amazonian forest fragments: a 32-year investigation, Biol. Conserv., 144, 56-67, 2011.

Lehman, S., Rajaonson, A., and Day, S.: Lemur responses to edge effects in the Vohibola III classified forest, Madagascar, Am. J. Primatol., 68, 293-299, 2006a.

Lehman, S., Rajaonson, A., and Day, S.: Edge effects and their influence on lemur density and distribution in Southeast Madagascar, Am. J. Phys. Anthropol., 129, 232-241, 2006 b.

Lehman, S., Rajaonson, A., and Day, S.: Edge effects on the density of Cheirogaleus major, Int. J. Primatol., 27, 1569-1588, 2006c.

Lehtinen, R. M., Ramanamanjato, J.-B., and Raveloarison, J. G.: Edge effects and extinction proneness in a herpetofauna from Madagascar, Biodivers. Conserv., 12, 1357-1370, 2003.

Lidicker, W. Z.: Responses of mammals to habitat edges: an overview, Landscape Ecol., 14, 333-343, 1999.

Martínez-Mota, R., Valdespino, C., Sánchez-Ramos, M. A., and Serio-Silva, J. C.: Effects of forest fragmentation on the physiological stress response of black howler monkeys, Anim. Conserv., 10, 374-379, 2007.

Mastromonaco, G. F., Gunn, K., McCurdy-Adams, H., Edwards, D. B., and Schulte-Hostedde, A. I.: Validation and use of hair cortisol as a measure of chronic stress in eastern chipmunks (Tamias striatus), Conserv. Physiol., 2, cou055, https://doi.org/10.1093/conphys/cou055, 2014.

McGoogan, K. C., Steffens, T., and Lehman, S.: Edge effects on home range size of Propithecus coquereli in northwest Madagascar, Am. J. Primatol., 71, Suppl: 1-27, abstract 127, https://doi.org/10.1002/ajp.20733, 2009.
Muller, M. N. and Wrangham, R. W.: Dominance, cortisol and stress in wild chimpanzees (Pan troglodytes schweinfurthii), Behav. Ecol. Sociobiol., 55, 332-340, 2004.

Murcia, C.: Edge effects in fragmented forests: implications for conservation, TREE, 10, 58-62, 1995.

Norscia, I., Carrai, V., and Borgognini-Tarli, S. M.: Influence of dry season and food quality and quantity on behavior and feeding strategy of Propithecus verreauxi in Kirindy, Madagascar, Int. J. Primatol., 27, 1001-1022, 2006.

Pride, E.: High faecal glucocorticoid levels predict mortality in ringtailed lemurs (Lemur catta), Biol. Letters, 1, 60-63, 2005.

Radespiel, U., Schulte, J., Burke, R. J., and Lehman, S. M.: Molecular edge effects in the Endangered golden-brown mouse lemur, Microcebus ravelobensis, Oryx, 53, 716-726, 2019.

Rakotoniaina, J. H., Kappeler, P. M., Ravoniarimbinina, P., Pechouskova, E., Hämäläinen, A. M., Grass, J., Kirschbaum, C., and Kraus, C.: Does habitat disturbance affect stress, body condition and parasitism in two sympatric lemurs?, Conserv. Physiol., 4, cow034, https://doi.org/10.1093/conphys/cow034, 2016.

Rangel-Negrín, A., Alfaro, J. L., Valdez, R. A., Romano M. C., and Serio-Silva, J. C.: Stress in Yucatan spider monkeys: effects of environmental conditions on faecal cortisol levels in wild and captive populations, Anim. Conserv., 12, 496-502, 2009.

Rangel-Negrín, A., Coyohua-Fuentes, A., Chavira, R., CanalesEspinosa, D., and Dias, P. A.: Primates living outside protected habitats are more stressed: the case of black howler monkeys in the Yucatán Peninsula, PloS one, 9, e112329, https://doi.org/10.1371/journal.pone.0112329, 2014.

Richard, A. F.: Behavioral variation: Case study of a Malagasy lemur, Bucknell University Press, Lewisburg, PA, USA, 1978.

Rimbach, R., Link, A., Heistermann, M., Gomez-Posada, C., and Heymann, E. W.: Effects of logging, hunting, and forest fragment size on physiological stress levels of two sympatric ateline primates in Colombia, Conserv. Physiol., 1, cot031, https://doi.org/10.1093/conphys/cot031, 2013a.

Rimbach, R. Heymann, E. W., Link, A., and Heistermann, M.: Validation of an enzymeimmunoassay for assessing adrenocortical activity and evaluation of factors that affect levels of fecal glucocorticoid metabolites in two New World primates, Gen. Comp. Endocr., 191, 13-23, 2013b.

Rudolph, K., Fichtel, C., Schneider, D., Heistermann, M., Koch, F., Daniel, R., and Kappeler, P. M.: One size fits all? Relationships among group size, health, and ecology indicate a lack of an optimal group size in a wild lemur population, Behav. Ecol. Sociobiol., 73, 132, https://doi.org/10.1007/s00265-019-2746-0, 2019.

Rudolph, K., Fichtel, C., Heistermann, M., and Kappeler, P. M.: Dynamics and determinants of glucocorticoid metabolite concentrations in wild Verreaux's sifakas, Horm. Behav., 124, 104760, https://doi.org/10.1016/j.yhbeh.2020.104760, 2020.

Schwitzer, C., Mittermeier, R. A., Johnson, S. E., Donati, G., Irwin, M., Peacock, H., Ratsimbazafy, J., Razafindramanana, J., Louis, E. E., Chikhi, L., Colquhoun, I. C., Tinsman, J., Dolch, R., LaFleur, M., Nash, S., Patel, E., Randrianambinina, B., Rasolofoharivelo, T., and Wright, P. C.: Averting lemur extinctions amid Madagascar's political crisis, Science, 343, 842-843, 2014.

Shutt, C., Setchell, J., and Heistermann, M.: Non-invasive monitoring of physiological stress in the western lowland gorilla (Gorilla gorilla gorilla): Validation of a faecal glucocorticoid assay and 
methods for practical application in the field, Gen. Comp. Endocr., 179, 167-177, 2012.

Tarlow, E. M. and Blumstein, D. T.: Evaluating methods to quantify anthropogenic stressors on wild animals, Appl. Anim. Behav. Sci., 102, 429-451, 2007.

Tecot, R. S., Irwin, M. T., and Raharison, J.-L.: Faecal glucocorticoid metabolite profiles in diademed sifakas increase during seasonal fruit scarcity with interactive effects of age/sex class and habitat degradation, Conserv. Physiol., 7, coz001, https://doi.org/10.1093/conphys/coz001, 2019.

Trillmich, J., Fichtel, C., and Kappeler, P. M.: Coordination of group movements in wild Verraux's sifakas (Propithecus verreauxi), Behaviour, 141, 1103-1120, 2004.

Vieilledent, G., Grinand, C., Rakotomalala, F. A., Ranaivosoa, R., Rakotoarijaona, J. R., Allnutt, T. F., and Achard, F.: Combining global tree cover loss data with historical national forest cover maps to look at six decades of deforestation and forest fragmentation in Madagascar, Biol. Conserv., 222, 189-197, 2018.
Vitousek, M. N., Taff, C. C., Hallinger, K. K., Zimmer, C., and Winkler, D. W.: Hormones and fitness: evidence for trade-offs in glucocorticoid regulation across contexts, Front. Ecol. Evol., 6, 42 pp., https://doi.org/10.3389/fevo.2018.00042, 2018.

Watson, J. E. M., Whittaker, R. J., and Dawson, T. P.: Habitat structure and proximity to forest edge affect the abundance and distribution of forest-dependent birds in tropical coastal forests of southeastern Madagascar, Biol. Conserv., 120, 311-327, 2004.

Zinner, D., Wygoda, C., Razafimanantsoa, L., Rasoloarison, R., Andrianandrasana, H. T., Ganzhorn, J. U., and Torkler, F.: Analysis of deforestation patterns in the central Menabe, Madagascar, between 1973 and 2010, Reg. Environ. Change, 14, 157-166, 2014.

Zuur, A. F., Ieno, E. N., Walker, N. J., Saveliev, A. A., and Smith, G. M.: Mixed effects models and extensions in ecology with R, Springer, New York, USA, 2009. 